\title{
O Parque Nacional do Viruá $(R R)$ e a possibilidade da criação de uma Estrada-Parque no seu entorno
}

\section{The Viruá National Park (RR, Brazil) and the possibility of creating a road park in your around}

\author{
Leila de Sena Cavalcante, Paulo dos Santos Pires
}

\section{RESUMO}

O contexto temático deste estudo situa-se na confluência do ecoturismo com as áreas protegidas, compreendidos como dois campos de interesse convergente quando contemplados plenamente no seu papel para a conservação da natureza. O objeto de análise é o Parque Nacional do Viruá, uma unidade de conservação federal localizada no município de Caracaraí a aproximadamente $197 \mathrm{~km}$ de Boa Vista, capital do Estado de Roraima. Por apresentar uma rica biodiversidade o parque possui um expressivo potencial para o ecoturismo, porém enfrenta um desafio no que diz respeito ao desenvolvimento deste tipo de atividade em seu interior, já que boa parte do seu potencial turístico, assim como a principal via de acesso ao mesmo e as áreas com possibilidade de construção de futuras instalações para recepção de visitantes estão situadas na "Estrada Perdida", fora dos limites do parque. Esta problemática induziu ao presente estudo, que teve como objetivo refletir sobre os possíveis benefícios que a transformação da "Estrada Perdida" numa área protegida do tipo estrada-parque, poderia levar ao Parque Nacional do Viruá e seu entorno. Trata-se de uma investigação de nível exploratório-descritivo, com abordagem qualitativa, utilizando como procedimentos metodológicos a revisão bibliográfica em livros, revistas e artigos científicos acerca do assunto, a pesquisa documental e a pesquisa de campo, que consistiu em entrevista com o gestor do Parque Nacional do Viruá. Os resultados do estudo apontaram que além dos benefícios socioambientais relacionados à proteção dos recursos naturais e culturais da região, a estrada-parque tende a produzir efeitos positivos também e, em especial, nos âmbitos econômico e social da unidade de conservação e de seu entorno regional.

PALAVRAS-CHAVE: Ecoturismo; Áreas Protegidas; Estrada-Parque; Parque Nacional do Viruá. 


\section{ABSTRACT}

The thematic context of this study lies at the confluence of ecotourism in protected areas, understood as two converging fields of interest as contemplated in its full role in the preservation of nature. The object of analysis is the Viruá National Park, a federal conservation unit in the municipality of Caracaraí approximately $197 \mathrm{~km}$ from Boa Vista, Roraima state capital. As its great biodiversity, the park has a significant potential for ecotourism, but faces an challenge with regard to developing this type of activity, since most of its tourism potential as well as the main access to the same and areas with possible future construction of facilities for the reception of visitors are located in "Lost Highway", outside the park boundaries. This problem led to this study, which aimed to reflect on the possible benefits that the transformation of "Lost Highway" in a protected area of the park-type road may lead to Viruá National Park and its surroundings. This is a research exploratory- descriptive, with qualitative approach, using as instruments the bibliographic review, magazines and scientific papers, documentary research and the field research, which consisted of an interview with the manager of the Viruá National Park. The results of the study showed that besides the social and environmental benefits related to the protection of natural and cultural resources of the region, the road-park may also have positive effects and, in particular in the economic and social unit of conservation and its surrounding region.

KEYWORDS: Ecotourism; Protected Areas; Park-Type Road; Viruá National Park.

\section{O contexto temático e o objeto de estudo}

A conservação dos recursos naturais é um tema que vem sendo bastante discutido nos últimos anos por cientistas, conservacionistas e estudiosos de todo o mundo. Segundo Milano (2005), isso tem ocorrido porque as relações do homem com a natureza, "tão antigas quanto a própria existência da humanidade", sofreram alterações significativas com o passar dos anos, decorrentes principalmente do processo civilizatório a que a sociedade esteve sujeita.

No Brasil, conforme Mittermeier et al (2005), até a primeira metade do século XX, a consciência da necessidade de conservação dos recursos naturais praticamente não existia. Apenas a partir da década de 1970, o país apresentou um avanço maior tanto na ação de conservação como no desenvolvimento da capacidade de conservação. Para o mesmo autor, tal fato foi evidenciado pela criação de um grande número de parques e reservas no país.

Em consonância com a Convention on Biological Biodiversity (www.biodiv.org), o Instituto Brasileiro do Meio Ambiente e Recursos Naturais Renováveis - IBAMA (1997) elenca quatro principais argumentos que explicam a necessidade de conservação da biodiversidade. São eles: 
-Suas contribuições econômicas diretas, através da utilização de uma imensa quantidade de produtos alimentares, farmacêuticos e de uso industrial derivados da fauna e da vegetação;

-Suas participações nos ciclos ambientais da Terra, tais como ciclos da água, dos climas, dos nutrientes, etc.;

-Seu valor estético paisagístico, que atrai as pessoas por sua beleza e seu "poder de fascinação";

-Suas justificativas éticas inerentes às próprias espécies, ou seja, seu valor por ela mesma e pelo próprio direito de existir.

A apropriação do termo "conservação", na sua acepção mais adequada à estratégia da conservação da biodiversidade, tem origem no documento de referência mundial "Estratégia Mundial para a Conservação" da União Internacional para a Conservação da Natureza e dos Recursos Naturais (UICN) que, em sua versão em português, publicada no Brasil em 1984, apresenta a seguinte definição:

\begin{abstract}
A gestão da utilização da biosfera pelo ser humano, de tal sorte que produza o maior benefício sustentado para as gerações atuais, mas que mantenha sua potencialidade para satisfazer às necessidades e às aspirações das gerações futuras. Portanto, a conservação é positiva e compreende a preservação, a manutenção, a utilização sustentada, a restauração e a melhoria do ambiente natural (UICN, 1984, p.1).
\end{abstract}

Percebe-se então que o conceito de conservação utilizado no documento da UICN é amplo e leva a uma reflexão cuidadosa e a um entendimento mais acurado para a sua aplicação. Com isso, Takahashi (2006, p. 2) enfatiza que

\begin{abstract}
...considerando que a conservação da natureza consiste no uso racional dos recursos, ela implica diretamente na preservação dos mesmos, onde o melhor uso é garantido por meio da geração de benefícios indiretos. Com isso, é mister enfatizar que tanto a conservação quanto a preservação da natureza devem integrar o planejamento do desenvolvimento do país.
\end{abstract}

Nesse sentido, a biodiversidade representa um recurso estratégico para o Brasil, país detentor de megadiversidade que, por este motivo, deve pensar a conservação da natureza como prioridade em suas políticas públicas, visando contribuir não só para a proteção dos seus recursos naturais, mas também para a sensibilização da sociedade quanto ao uso sustentável destes.

Considerando esse contexto e a importância dos parques nacionais para a conservação da natureza e, consequentemente, para a manutenção 
da biodiversidade, adotou-se como objeto de estudo, o Parque Nacional do Viruá, uma unidade de conservação federal instituída por Decreto de 29 de abril de 1998, com o objetivo de "proteger e preservar amostras dos ecossistemas ali existentes e possibilitar o desenvolvimento da pesquisa científica e de programas de educação ambiental' (Decreto $\mathrm{s} / \mathrm{n}, 1998$, art. 1ํ).

Localizado no município de Caracaraí, a aproximadamente $197 \mathrm{~km}$ de Boa Vista, capital do Estado de Roraima, segundo o seu Projeto de Ampliação (2010), o parque faz parte de um mosaico de cinco unidades de conservação federais, situadas no Estado, compreendendo uma área contínua de mais de 1.200 .000 hectares (formado pelos Parques Nacionais da Serra da Mocidade e Viruá, pelas Estações Ecológicas Niquiá e Caracaraí, e pela Floresta Nacional Anauá) (Figura 1). Nesse mosaico, o Parque Nacional do Viruá destaca-se em relação à gestão integrada (proteção, turismo, educação ambiental e pesquisa), sendo a única unidade de conservação apoiada pelo Programa ARPA (Áreas Protegidas da Amazônia) na região.

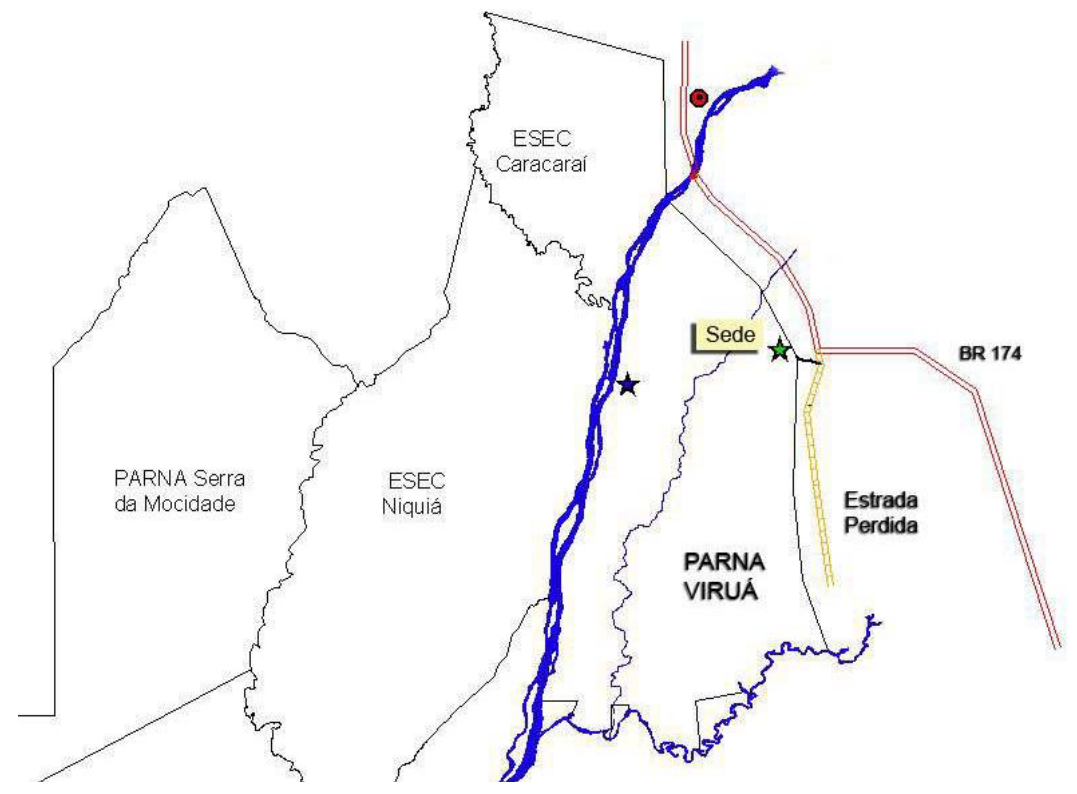

Figura 1: Localização e limites do Parna Viruá e da "estrada perdida" no contexto do mosaico de UCs da região. Fonte: MMA (2010).

Figure 1: Location and boundaries of Parna Viruá and "Lost Highway" in the context of protected areas mosaic of the region. Source: MMA (2010).

Incrustado em plena Amazônia Brasileira, uma das regiões de maior biodiversidade do planeta, o parque possui um expressivo potencial para o turismo ecológico, já que resguarda um "vasto patrimônio genético de flora e fauna", "paisagens de grande beleza cênica, ecossistemas representativos de campinaranas e recursos hídricos e edáficos com alto grau de vulnerabilidade a perturbações antrópicas" (MMA, 2010, p. 21).

No entanto, mesmo apresentando tamanha potencialidade, o Parque Nacional do Viruá encara um desafio no que diz respeito ao desenvolvimento das atividades de turismo. Boa parte do potencial turístico do parque, assim como a principal via de acesso ao mesmo e as áreas com 
possibilidade de construção de instalações para recepção de visitantes estão situadas na "Estrada Perdida", estrada está fora dos limites do parque.

A "Estrada Perdida" é um antigo trecho abandonado da BR-174 e abrange uma extensão de $40 \mathrm{~km}$ de estrada de terra em boas condições, situada no limite leste do parque, sendo o único acesso terrestre possível ao seu interior. Esta estrada permite o acesso a toda a formação de campinas da porção leste da unidade, ao sul da UC e ao Abrigo Rústico da Serra do Preto, regiões de importância estratégica para a proteção e o uso público da UC. (MMA, 2010). A partir do contexto exposto, esse estudo aborda os possíveis benefícios que a transformação da "Estrada Perdida" numa estrada-parque poderá trazer ao Parque Nacional do Viruá e seu entorno.

Para tanto, seguem-se a fundamentação teórica pertinente na qual são tratados temas como a conservação da natureza, o processo de criação de áreas protegidas e o Sistema Nacional de Unidades de Conservação (SNUC), o turismo nos parques nacionais brasileiros, os conceitos de estradas-parque e a caracterização do Parque Nacional do Viruá, objeto de estudo desse trabalho. Em seguida, são apresentados os procedimentos metodológicos bem como a discussão dos resultados preliminares obtidos e as considerações finais apontando também algumas limitações desta abordagem.

\section{Breve histórico sobre o processo de criação de áreas protegidas e 0 Sistema Nacional de Unidades de Conservação (SNUC)}

Ao tratar do Sistema Nacional de Unidades de Conservação, é necessário compreender, num primeiro momento, o processo de criação das primeiras áreas protegidas.

Assim, em âmbito mundial, o primeiro parque nacional, oficializado e reconhecido, foi criado nos Estados Unidos, em 1872: o Parque Nacional de Yellowstone. Para Braga (2011, p. 4), "foi a beleza cênica da paisagem da região que incitou a necessidade de sua preservação para resguardar o local da expansão para o Oeste e para garantir que as futuras gerações também pudessem desfrutar da natureza ali retratada". Após o nascimento de Yellowstone, a ideia de proteção de áreas naturais, proibindo sua exploração desordenada e permitindo o seu uso para fins de recreação e educação ambiental, ganhou expressiva divulgação, difundindo-se por vários países do mundo, como Canadá, Nova Zelândia, Austrália, África do Sul e México, os quais constituíram seus primeiros parques e reservas ainda no século XIX, entre os anos de 1885 e 1898.

No Brasil, de acordo com Jorge Pádua (1997), o engenheiro e político André Rebouças foi o responsável, em 1876, pela primeira proposta de criação de Parques Nacionais, tendo sugerido a criação dos parques nacionais da Ilha do Bananal, em Tocantins e Sete Quedas, no Paraná. Sua tentativa, porém, não obteve êxito e o primeiro parque brasileiro, o Parque Nacional de Itatiaia, no Rio de Janeiro, foi instituído apenas em 1937. Depois deste, em 1939, surgiram os parques nacionais do Iguaçu (PR) e o da Serra dos Órgãos (RJ). 
A partir de então e decorridas seis décadas, com ampla participação da sociedade, através de setores governamentais, organizações ambientalistas e outros grupos políticos, é que se estabeleceu no Brasil o Sistema Nacional de Unidades de Conservação da Natureza (SNUC), instituído pela Lei oㅜ 9.985, de 18 de Julho de 2000, a qual estabelece critérios para a criação, implantação e gestão das unidades de conservação. Conforme a lei, unidade de conservação é entendida como

O espaço territorial e seus recursos ambientais, incluindo águas jurisdicionais, com características naturais relevantes, legalmente instituídos pelo Poder Público, com objetivos de conservação e limites definidos, sob regimes especiais de administração, aos quais se aplicam garantias adequadas de proteção. (BRASIL, 2000).

Considerando a definição do SNUC, é importante esclarecer que, como declara Milano (2005, p. 4),

[...] área protegida no Brasil é um termo genérico, enquanto unidade de conservação uma condição específica. A primeira é uma condição genérica da lei, auto aplicável, já a segunda requer ato próprio para seu estabelecimento, além de definição de limites e objetivos específicos. Dessa forma, as unidades de conservação serão sempre, de um ponto de vista legal e técnico, áreas protegidas, por outro lado, estas não necessariamente constituem unidades de conservação.

Dados do ICMBio (2015) apontam a existência de 320 Unidades de Conservação no país, geridas pelo órgão, as quais estão divididas em dois grandes grupos - Grupo de Proteção Integral e Grupo de Uso Sustentável , e classificadas por categorias, como mostra o Quadro 1.

Quadro 1: categorias de Unidades de Conservação.

Table 1: Protected Areas categories.

\begin{tabular}{|l|l|}
\hline \multicolumn{1}{|c|}{ Grupo de Proteção Integral } & \multicolumn{1}{c|}{ Grupo de Uso Sustentável } \\
\hline Estação Ecológica (ESEC) & Área de Proteção Ambiental (APA) \\
\hline Reserva Biológica (REBIO) & Área de Relevante Interesse Ecológico (ARIE) \\
\hline Parque Nacional (PARNA) & Floresta Nacional (FLONA) \\
\hline Monumento Natural (MN) & Reserva Extrativista (RESEX) \\
\hline Refúgio da Vida Silvestre (REVIS) & Reserva de Fauna (REFAU) \\
\hline- & Reserva de Desenvolvimento Sustentável (RDS) \\
\hline- & Reserva Particular do Patrimônio Natural (RPPN) \\
\hline
\end{tabular}

Fonte: Elaborado com base em Brasil (2000).

Source: Based in Brasil (2000) 
Segundo o ICMBio (2015), o Grupo de Proteção Integral, ao qual pertence a categoria estabelecida para o Parque Nacional do Viruá, objeto desse estudo, é composto por unidades de conservação que têm como objetivo principal

Preservar a natureza, livrando-a o quanto possível, da interferência humana; nelas, como regra, só se admite o uso indireto dos recursos naturais, isto é, aquele que não envolve consumo, coleta, dano ou destruição, com exceção dos casos previstos na Lei do SNUC.

De acordo com o MMA (2015) atualmente são 71 os parques nacionais criados no Brasil, porém, não necessariamente implantados e efetivamente regulamentados e geridos através de Planos de Manejo. Como se verá no item a seguir, a categoria parque, com base nos objetivos de conservação do SNUC é a melhor vocacionada para o ecoturismo, a recreação e a educação ambiental em contato com a natureza.

\title{
O turismo nos parques nacionais brasileiros
}

No Brasil, a Lei do SNUC ressalta que os parques nacionais podem ser definidos como

\begin{abstract}
A mais popular e antiga categoria de Unidades de Conservação. Seu objetivo, segundo a legislação brasileira, é preservar ecossistemas de grande relevância ecológica e beleza cênica, possibilitando a realização de pesquisas científicas, realização de atividades educacionais e de interpretação ambiental, recreação e turismo ecológico, por meio do contato com a natureza (BRASIL, 2000).
\end{abstract}

Por se configurar num espaço voltado não somente à preservação, os parques nacionais se destacam, em especial, pelo grande potencial que possuem para o desenvolvimento de atividades de recreação e turismo. No entanto, mesmo com esta potencialidade evidente, Jorge Pádua (2010, p. 1) informava que dos 67 Parques Nacionais que o país então possuía, apenas 20 estavam abertos à visitação pública. Com base nisso, a autora reforça a função primordial dos parques (proteção), mas insiste na ideia de que "a melhor forma de se envolver mais pessoas no apreço às áreas protegidas é a possibilidade de visitá-las" (idem, p. 21).

O Governo Federal em parceria com os ministérios do Turismo (MTur), do Meio Ambiente (MMA), com o Instituto Brasileiro de Turismo (EMBRATUR) e o Instituto Chico Mendes de Conservação da Biodiversidade (ICMBio) criou, em 2008, o Programa de Turismo nos Parques, que estabeleceu prioridades para 25 Parques Nacionais. Porém, devido ao fato das regiões e dos municípios abrangidos por estes parques se encontrarem em diferentes fases de implementação do turismo, para um primeiro 
momento, foram determinados, na ocasião, 6 parques nacionais como prioritários para investimentos e desenvolvimento de ações conjuntas, sendo eles sendo os Parques Nacionais Aparados da Serra (RS/SC); Chapada dos Veadeiros (GO); Serra dos Órgãos (RJ); Serra da Capivara (PI) e Jaú (AM) e, ainda, 4 parques para investimentos consolidados em parceria com a iniciativa privada por meio dos editais para concessão de serviços de apoio ao turismo, tais como os Parques Nacionais do Iguaçu (PR); Marinho de Fernando de Noronha (PE); Marinho dos Abrolhos (BA) e Tijuca (RJ).

De modo geral, o programa "visa estruturar e promover o turismo nos Parques inseridos no Sistema Nacional de Unidades de Conservação $S N U C$ ", contribuindo "para o desenvolvimento local e regional, valorizando o patrimônio natural e cultural e promovendo a aproximação entre sociedade e natureza" (MMA, 2008, p. 4-5).

Nesse sentido, nota-se que o Programa de Turismo nos Parques é apenas um exemplo de alternativa de incentivo à visitação nos parques nacionais brasileiros, a qual deve ser sempre estimulada, uma vez que a manutenção de parques fechados ou mesmo sem condições mínimas para recepção de visitantes é impeditivo à proteção de seus ecossistemas e ao desenvolvimento sociocultural da região em que estão inseridos.

Segundo o último Relatório de Gestão do ICMBio (ICMBio, 2013), os parques nacionais brasileiros em 2013 receberam 5.941.857 visitantes. Contudo, é importante ressaltar que, além de problemas relacionados à infraestrutura, à fiscalização, ao acesso, ao monitoramento, problemas fundiários entre outras dificuldades enfrentadas pelos parques nacionais, restringem a visitação nos mesmos. É o que acontece, por exemplo, no Parque Nacional do Viruá, em Roraima. Além da inexistência de infraestrutura turística no local, o PARNA Viruá possui as condições de maior potencial para o turismo localizados na "Estrada Perdida", estrada esta não pertencente à área demarcada para o parque.

\section{Estradas-Parque}

Para Dourojeanni (2003), os Estados Unidos deram origem ao nome e ao conceito de estradas-parque, onde essas áreas protegidas são denominadas de parkways e geridas pelo Serviço de Parques (US Park Service) ou pelos serviços de parques estaduais, em coordenação com o respectivo departamento de estradas de rodagem.

Embora não seja um tema novo no Brasil, tendo sido debatido desde a década de 1970, as estradas-parque não são consideradas categoria de unidade de conservação pela Lei ำ 9.985/2000 do SNUC, tendo sido incluídas apenas em algumas legislações estaduais. A respeito disso, Dourojeanni (2003, p. 16) afirma inclusive que "a América Latina e o Brasil, ao não terem adotado as estradas-parque, desperdiçaram uma excelente oportunidade de fomentar o turismo, impulsionar a economia local e reduzir riscos de acidente".

No que se refere aos conceitos de estradas-parque, dentre os poucos encontrados na literatura, Conde (2009) realça o da SOS Mata Atlântica, que diz: 
Estrada Parque é um museu permanente de percurso que atravessa Unidades de Conservação ou áreas de relevante interesse ambiental e paisagístico, implantado com o objetivo de aliar a preservação ambiental ao desenvolvimento sustentável da região, através do fomento ao ecoturismo e às atividades de educação ambiental, de lazer e culturais. Trata-se de uma classificação especial para rodovias e estradas localizadas em áreas de exuberância cênica e de relevante interesse patrimonial, quer seja natural, ambiental, arqueológico, cultural ou paisagístico, que podem ser tombadas ou especialmente protegidas (CONDE, 2009, p. 156).

Considerando tal definição e com base no levantamento realizado pelo referido autor, demonstra-se por meio do Quadro 2 a seguir alguns importantes exemplos de estradas-parque situadas no Brasil.

Quadro 2: Sinopse das principais Estradas-Parque do Brasil.

Table 2 : Summary of the main Park-Type Road of the Brazil.

\begin{tabular}{|c|c|c|c|}
\hline Denominação & Localização & Ano de criação & Característica \\
\hline $\begin{array}{c}\text { Estrada Parque } \\
\text { do Pantanal }\end{array}$ & MS & 1993 & $\begin{array}{l}\text { Formação de uma área de } \\
\text { interesse turístico, inserida dentro } \\
\text { do ecossistema do Pantanal e } \\
\text { desenvolve implementação de } \\
\text { ações de gestão participativa. }\end{array}$ \\
\hline $\begin{array}{l}\text { Estrada Parque } \\
\text { APA do rio Tietê } \\
\text { ou Estrada } \\
\text { Parque do ltu }\end{array}$ & SP & 1996 & $\begin{array}{l}\text { Proposta de utilizar a Estrada dos } \\
\text { Romeiros como elo para } \\
\text { consolidação de esforços na } \\
\text { conservação da região, } \\
\text { transformando-a em uma estrada } \\
\text { parque, com a ideia de museu } \\
\text { permanente de percurso para o } \\
\text { desenvolvimento sustentado do } \\
\text { local. }\end{array}$ \\
\hline $\begin{array}{l}\text { Estrada Parque } \\
\text { da Serra do } \\
\text { Guararu }\end{array}$ & SP & 2002 & $\begin{array}{l}\text { Criação de um processo de } \\
\text { integração para a preservação do } \\
\text { patrimônio turístico e ambiental. }\end{array}$ \\
\hline $\begin{array}{l}\text { Estrada Parque } \\
\text { Serra dos } \\
\text { Pirineus }\end{array}$ & GO & 2009 & $\begin{array}{l}\text { Ligação de dois municípios de } \\
\text { interesse ambiental e histórico, } \\
\text { cortando um parque e uma APA. } \\
\text { (Em processo de implementação). }\end{array}$ \\
\hline
\end{tabular}

Fonte: Elaborado com base em Conde (2009).

Source : Based on Conde (2009).

Nota-se no quadro que as características das estradas-parque são semelhantes, sendo evidenciada em todas elas a preocupação com a preservação aliada ao uso sustentável dos recursos, principalmente através das atividades de turismo. 
Por esse motivo, entende-se que a criação de estradas-parque é uma alternativa viável para áreas com relevância ambiental e turística, ou seja, que necessitem tanto da proteção de seus recursos naturais/culturais, mas que também apresentem grande potencial para o turismo, como é o caso da "Estrada Perdida", localizada na porção leste do Parque Nacional do Viruá.

\section{Potencialidades e limitações para o turismo no Parna Viruá}

De acordo com o Projeto de Ampliação do Parque Nacional do Viruá, publicado pelo Ministério do Meio Ambiente - MMA em 2010, o referido parque foi instituído em 1998 por meio de convenção internacional, da qual o Brasil é signatário. Tal convenção presume a destinação de $10 \%$ dos ecossistemas existentes no país em Unidades de Conservação.

Por seu solo inapto à agricultura, as terras hoje pertencentes ao parque haviam sido designadas pelo INCRA, desde a década de 1980, para a então Secretaria Especial de Meio Ambiente - SEMA, com o intuito de se implantar uma unidade de conservação na categoria estação ecológica. No entanto, o que ocorreu foi a criação do PARNA Viruá pelo então Instituto Brasileiro do Meio Ambiente e dos Recursos Naturais Renováveis - IBAMA no ano de 1998.

Situado no município de Caracaraí, no Estado de Roraima, o parque conta com uma área de 227 mil hectares, numa região de grande importância para a conservação da biodiversidade. Conforme documento do MMA (2010, p. 4),

[...] nesta região estão localizados os mais extensos mosaicos de campinas e campinaranas do mundo. Estes ecossistemas, formados sobre areias brancas (quartzosas), sustentam altíssima diversidade de espécies da fauna, especialmente peixes, aves e mamíferos, além de abrigar inúmeras nascentes de rios em áreas de grande fragilidade ambiental.

Devido a sua paisagem bastante heterogênea, marcada pela presença de florestas, campinas, campinaranas, banhados, lagoas e buritizais, o parque possui um número expressivo de espécies da fauna silvestre. A publicação do MMA (2010) registra que são "mais de 550 espécies de peixes que vivem em seus rios, igarapés e lagos, e 500 espécies de aves em seus ambientes diversificados", o que indica um grande potencial desta UC para a observação de mamíferos e aves, bem como para outras práticas de ecoturismo, educação ambiental e pesquisa científica.

Todavia, no que concerne especificamente ao turismo, apesar de seu expressivo potencial, o parque apresenta alguns obstáculos, dentre os quais se enfatiza àquele de maior preocupação para o gestor da UC nos dias atuais: a localização inadequada de alguns limites do parque, em especial, a leste, em que está situada a "Estrada Perdida". O Projeto de Ampliação do 
parque (MMA, 2010, p. 8) explica que, por determinação da Comissão encarregada por sua criação,

\begin{abstract}
Áreas de importância estratégica para o gerenciamento e preservação da UC foram mantidas fora de seus limites para evitar qualquer possibilidade de problema fundiário, criandose assim uma UC inteiramente regularizada, mas com problemas de delimitação que comprometem gravemente sua integridade.
\end{abstract}

Dessa forma, áreas como as que compreendem a "Estrada Perdida", onde se encontram as nascentes de grande parte dos igarapés da bacia do rio Iruá - rio que dá nome ao parque - estão fora dos limites do mesmo, comprometendo assim seriamente a preservação de ecossistemas terrestres e aquáticos e tornando vulneráveis à extinção muitos elementos da fauna. É importante frisar ainda que, de acordo com a análise técnica feita por gestores da UC e pesquisadores da equipe responsável pelo Plano de Manejo do Parque,

O rio Iruá e seus afluentes sustentam a mais elevada riqueza de peixes já registrada em unidade de conservação na Amazônia Brasileira. Mais de 285 espécies foram registradas em uma única expedição de pesquisa, e um total de 423 foram registradas nos igarapés, rios e lagos da UC e entorno. Esta elevada diversidade da fauna aquática é reflexo da grande variedade de ambientes encontrados nestes igarapés, cuja integridade está totalmente associada às condições de suas nascentes (MMA, 2010, p. 10).

A "Estrada Perdida", devido à sua localização estratégica, fornece acesso tanto ao rio Iruá como a outras regiões de grande importância para a proteção e o uso público do parque. Logo, enquanto área de relevante biodiversidade e potencialidade turística, depreende-se que há uma necessidade premente no que se refere à inserção dessa estrada aos limites do parque, sendo uma das alternativas possíveis, e que o presente estudo pretende sustentar, a sua transformação numa estrada-parque. Essa ação pode contribuir para a efetiva preservação de seu patrimônio e o pleno aproveitamento de suas potencialidades naturais.

Embora com grande potencial para o turismo, o parque ainda não se encontra aberto à visitação. As visitas ao PARNA Viruá são realizadas de forma esporádica por grupos geralmente de estudiosos das áreas de Biologia, Geografia, etc. e estudantes de cursos de Ensino Fundamental, Médio, Técnico e Superior, o que significa dizer que o parque não recebe demanda de turistas. Isso ocorre, porque, além da falta de infraestrutura para recepção de visitantes, a UC enfrenta um grande entrave para 0 desenvolvimento do turismo em seu interior: a não incorporação da estrada perdida à área do parque, foco desta abordagem.

De acordo com o ICMBio (2010) a situação fundiária das áreas relevantes para ampliação do Parque Nacional do Viruá, na Figura 2 
representadas em verde, apresentam condições que favorecem amplamente a condução deste processo.

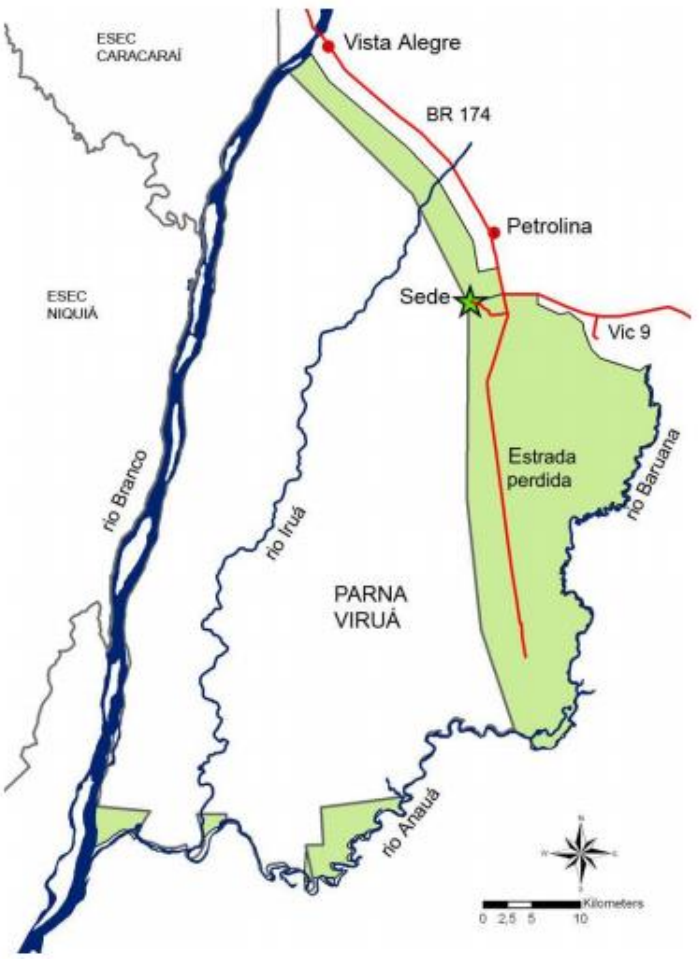

Figura 3: Áreas relevantes para ampliação do Parque Nacional do Viruá. Fonte: ICMBio (2010).

Figure 3: Relevant areas for expansion of Viruá National Park. Source : ICMBio (2010).

Os terrenos são em sua maior parte arrecadados pelo INCRA, a ocupação é inexistente em praticamente toda sua extensão, destacando-se a grande porção no limite leste do parque dentro da qual ocorre a estrada perdida.

\section{Procedimentos metodológicos}

Para alcançar o objetivo desse trabalho que é promover uma reflexão sobre os possíveis benefícios que a transformação da "Estrada Perdida" numa estrada-parque poderá levar ao Parque Nacional do Viruá e seu entorno, realizou-se uma pesquisa exploratória com abordagem qualitativa.

De acordo com Malhotra (2006), a pesquisa em nível exploratório é usada na maioria das vezes como ponto de partida de toda a concepção da pesquisa. Diferencia-se por explorar problemas específicos, determinar critérios e promover um maior entendimento acerca do tema investigado, possibilitando a relação com a realidade a partir de fatos observados e informações obtidas através de documentos ligados ao objeto de estudo.

Para a obtenção dos dados secundários, procedeu-se a revisão bibliográfica em livros, revistas e artigos científicos acerca do assunto, bem como a pesquisa documental a partir de publicações do Ministério do Meio Ambiente e do ICMBio.

A análise qualitativa dos dados coletados se deu a partir da sistematização das informações obtidas por meio da entrevista com o gestor 
do parque e da compreensão e apreciação crítica de documentos relacionados à $U C$, aos quais se teve acesso. Tal análise considerou também o marco teórico adotado no estudo, envolvendo os paradigmas da conservação da natureza, os princípios do SNUC e as características do ecoturismo e de uma estrada-parque.

\section{Considerações sobre os possíveis benefícios da transformação da "Estrada Pperdida" em Eestrada-Parque}

Por suas peculiaridades, o Parque Nacional do Viruá apresenta grande potencial para uso público, principalmente no que diz respeito à sua visitação para fins turísticos e recreativos, haja vista que o parque é também uma das poucas UCs da Amazônia que possuem acesso por estrada, feito pela BR-174 e percorrendo-se $190 \mathrm{~km}$ de rodovia asfaltada a partir de Boa Vista, capital de Roraima, ou $600 \mathrm{~km}$ a partir de Manaus, no Amazonas, e mais $7 \mathrm{~km}$ de estrada de terra em bom estado de conservação.

Contudo, se, por um lado, essa maior acessibilidade é positiva, garantindo ao parque muitas vantagens em relação à sua operacionalização e potencial de visitação, por outro, "a proximidade do eixo principal da malha rodoviária estadual representa uma série de riscos à integridade da UC, notadamente no que se refere à expansão da fronteira agrícola e ao tráfico de fauna silvestre" (MMA, 2010, s/p).

Conforme o Projeto de Ampliação (MMA, 2010), o Parque Nacional do Viruá está localizado em uma região conhecida como "pantanal setentrional", constituída por solos de areias brancas de baixíssima fertilidade, sujeitos a fortes inundações sazonais.

Um estudo desenvolvido por Vale Júnior (2007) apud MMA (2010) mostrou que os solos da região são compostos essencialmente por areias (quartzo), logo, pobres em nutrientes e com capacidade de se manterem encharcados ou inundados por longos períodos de tempo, o que confirma total inaptidão dos mesmos para o uso agrícola ou pastoril. Em relação a tal condição, o mesmo estudo constata que

[...] os solos dominantes da área de abrangência deste parecer apresentam classe VIIla,s quanto a capacidade de uso, ou seja, terras impróprias para cultura, pastagem ou reflorestamento, podendo servir apenas como abrigo da fauna silvestre, preservação da flora, como ambiente para recreação ou para fins de armazenamento de água (VALE JÚNIOR, 2007 apud MMA, 2010, p. 12).

Rangel apud MMA (2010, p. 12) também reforçou a impropriedade dos solos dessa região para a agricultura e o assentamento humano e enfatizou que haveria "riscos graves de desertificação, contaminação por fertilizantes e agrotóxicos de toda a UC e perda de biodiversidade, caso tentativas de projetos agrícolas fossem desenvolvidas nas campinas adjacentes ao Parque". 
Diante destas condições torna-se imprescindível ao PARNA Viruá uma alternativa que possa garantir a preservação da riqueza biológica da área do entorno do parque, mais especificamente da "Estrada Perdida", bem como o uso sustentável de seus recursos a partir de atividades de turismo bem planejadas e devidamente monitoradas.

De acordo com Takahashi (2004), a atividade turística e recreativa tem sido vista como um dos melhores meios para conservar áreas naturais, desde que avaliadas as consequências negativas do uso inadequado dessas áreas. Em referência ao ecoturismo, o Projeto de Ampliação do Parque (MMA, 2010) expõe com clareza a vocação natural da unidade de conservação para esta atividade como também confirma a necessidade de incorporação da "Estrada Perdida" ao parque.

As campinas do PARNA Viruá possuem atributos de grande valor para o turismo ecológico, entre eles paisagens de grande beleza e uma elevada riqueza de aves e mamíferos. Roteiros turísticos nesta região da UC deverão ser responsáveis por um alto fluxo de visitação, em razão da elevada qualidade dos passeios a serem realizados por um baixo custo. A implantação destes roteiros dependerá do uso e manutenção da "estrada perdida", e da preservação dos atributos naturais desta região, sendo imprescindível para isto a incorporação da área de campinas da "estrada perdida", sob o domínio da União, aos novos limites da unidade (MMA, 2010, p. 14).

Para que essa incorporação ocorra, entende-se que a "Estrada Perdida" deve ser transformada numa estrada-parque. Como esta não é uma categoria pertencente ao Sistema Nacional de Unidades de Conservação, será necessária a inserção da estrada-parque na legislação estadual de Roraima, como já realizada em outros estados do Brasil como São e Paulo e Mato Grosso do Sul, ou mesmo a criação, no entorno da estrada, de uma APA (Área de Proteção Ambiental). Esta categoria de unidade de conservação pode possibilitar o ordenamento do uso sustentável do solo e a conservação da natureza, favorecendo a proteção do cenário do entorno da estrada e se constituindo em uma área de amortecimento para o próprio parque, como ocorre em alguns parques nacionais brasileiros. Seja qual for a medida a ser tomada, cabe lembrar que

No caso brasileiro, uma estrada-parque é uma unidade de conservação de uso direto, pois se associa a uma estrada, construída com características adequadas para o turismo, com uma área suficientemente protegida para garantir a qualidade paisagística natural ou tradicional (DOUROJEANNI, 2003, p. 17).

Segundo Conde (2009, p.158), "a criação da estrada-parque como figura jurídica, com gestão compartilhada entre o poder público e os diversos grupos de interesse da sociedade", passa a suscitar um novo olhar sobre as 
regiões onde estão inseridas. Ela pode tornar-se uma forma de conduzir e alinhar ações e interesses nas áreas de entorno.

A transformação da "Estrada Perdida" em estrada-parque no PARNA Viruá surge então como uma oportunidade de se instituir esse novo olhar sobre a região, possibilitando 0 avanço na organização social da comunidade de Caracaraí, como também a reestruturação nas cadeias produtivas locais. A gestão e o alinhamento das ações dos governos locais e da comunidade podem representar o fim de um longo processo de estagnação do município, cuja economia encontra-se baseada apenas na atividade pesqueira, em programas assistencialistas e à insipiente agricultura de subsistência.

Procurando melhor evidenciar os possíveis benefícios que a transformação da "Estrada Perdida" numa estrada-parque poderá levar ao Parque Nacional do Viruá e seu entorno, elaborou-se um quadro de possíveis benefícios (Quadro 3), abrangendo os campos econômicos, ambientais/culturais e sociais. Tal classificação é resultado de uma adaptação feita a partir do quadro de benefícios potenciais do turismo em unidades de conservação obtido em Takahashi (2004).

Quadro 3: Possíveis benefícios advindos do turismo a partir da transformação da "Estrada Perdida" em Estrada-Parque.

Table 3: Possible benefits from tourism from the transformation of " Lost Highway " in Road-Park.

\begin{tabular}{|c|c|}
\hline CLASSIFICAÇÃO & BENEFÍCIOS \\
\hline Econômicos & $\begin{array}{l}\text { - Estímulo a novas empresas da cadeia produtiva do turismo e } \\
\text { diversificação da economia local; } \\
\text { - Maior oferta de emprego e renda para a comunidade; } \\
\text {-Possibilidade de capacitação da comunidade às novas atividades } \\
\text { econômicas ligadas direta e indiretamente ao turismo; } \\
\text { - Reestruturação de cadeias produtivas de Caracaraí, município onde } \\
\text { o parque está localizado; } \\
\text {-Estímulo à manufatura de bens locais. }\end{array}$ \\
\hline Ambientais/Culturais & $\begin{array}{l}\text { - Impedimento às tentativas de grilagem de terra na área de } \\
\text { nascentes dos igarapés do parque; } \\
\text { - Redução de riscos graves de desmatamento, desertificação, } \\
\text { assoreamento, contaminação por fertilizantes e agrotóxicos de } \\
\text { toda a UC; } \\
\text { - Conservação da biodiversidade do parque; } \\
\text { - Valorização e proteção de recursos atualmente imperceptíveis pela } \\
\text { comunidade; } \\
\text {-Apoio ao desenvolvimento de pesquisas científicas na área do } \\
\text { parque e seu entorno. }\end{array}$ \\
\hline Sociais & $\begin{array}{l}\text { - Oportunidade de envolvimento da comunidade local, melhora da } \\
\text { auto estima, e da noção de pertencimento; } \\
\text { - Estímulo à promoção de cultura e tradições locais pela comunidade } \\
\text { de Caracaraí; } \\
\text { - Possibilidade de aumento no nível educacional da comunidade a } \\
\text { partir de cursos de capacitação; } \\
\text { - Apoio à educação ambiental, melhorando o nível de consciência } \\
\text { acerca da conservação em visitantes e comunidade local; } \\
\text {-Estímulo à comunidade para o aprendizado de línguas e culturas } \\
\text { estrangeiras. }\end{array}$ \\
\hline
\end{tabular}

Fonte: Elaborado com base em Takahashi (2004).

Source: Based on Takahashi (2004). 
Em síntese, os benefícios econômicos referem-se mais especificamente ao aumento de oportunidades econômicas, na região, provenientes do turismo. Já os benefícios ambientais/culturais dizem respeito à proteção do patrimônio natural e cultural local e, finalmente, os benefícios sociais tratam da melhoria da qualidade de vida da comunidade, onde a UC está situada, a partir da atividade turística.

Diante do significado e alcance dos possíveis benefícios apontados, fica claro que a criação da estrada-parque no entorno do Parque Nacional do Viruá é uma alternativa relevante para a sua valorização enquanto área protegida e, por isso, precisa ser pensada de forma coerente e estratégica pelos segmentos sociais de interesse e responsáveis institucionais pelo desenvolvimento local e do Estado de Roraima.

\section{Considerações finais}

Embora os resultados da pesquisa não tenham explicitado todos os aspectos envolvidos no processo de transformação da "Estrada Perdida" em estrada-parque, acredita-se que esta abordagem possa cumprir com seu objetivo central: o de promover uma reflexão sobre os possíveis benefícios que esta transformação poderá levar ao Parque Nacional do Viruá, em Roraima.

Evidenciou-se a vocação e o potencial do parque para o turismo com o apontamento dos prováveis benefícios advindos dessa atividade através da criação da estrada-parque. Além dos benefícios ambientais/culturais relacionados à proteção dos recursos naturais e culturais da região, argumentou-se que a estrada-parque poderá produzir efeitos positivos também e, em especial, nos âmbitos econômico e social da unidade de conservação e suas adjacências. Pode-se inferir inclusive que esses efeitos impactariam de forma ainda mais significativa a localidade, já que resultaria em mudanças na sua economia, bem como na educação e na qualidade de vida da comunidade de Caracaraí, município em que o PARNA Viruá está localizado.

No entanto, como esse trabalho deteve-se apenas em uma reflexão acadêmica, ainda que associada a uma dimensão empírica, desde já se sugere que sejam desenvolvidas outras pesquisas eminentemente empíricas com a obtenção de dados primários a campo que possibilitem, por exemplo: a) investigação sobre a percepção de todos os atores envolvidos no processo de criação do parque (gestores da UC e do poder público local e regional, moradores do entorno, entre outros); b) identificação do perfil dos atuais e potenciais visitantes do parque e das opiniões dos mesmos acerca das condições dos equipamentos e serviços oferecidos hoje na UC; e c) mensuração, através de métodos como o de valoração contingente, sugerido por Serra et al (2004), do retorno econômico que uma estrada-parque pode gerar a partir do seu uso. Tais estudos mai aprofundados poderão proporcionar às esferas de decisão um embasamento maior sobre a importância e a necessidade de criação da estrada-parque, oferecendo inclusive subsídios para a elaboração do seu futuro projeto de concepção.

Portanto, a presente reflexão sobre a possibilidade de transformação da "Estrada Perdida" em estrada-parque no entorno do Parque Nacional do Viruá, também procurou chamar a atenção para a viabilidade em ampliar e potencializar o uso público de um parque nacional por meio da agregação de uma categoria de área protegida atualmente não inclusa no Sistema Nacional 
de Unidades de Conservação, porém com reconhecido potencial para a valorização social daquelas UCs que a exemplo dos parques, contemplam entre os seus objetivos primários a conservação da natureza, o ecoturismo e a educação ambiental.

\section{Referências bibliográficas}

BRAGA, A. S. Parques nacionais nos Estados Unidos: Parque Nacional de Yellowstone e Parque Nacional de Yosemite. Publicado em 02/2011. Disponível em <http://jus.com.br/revista/texto/19774/parques-nacionais-nos-estados-unidosparque-nacional-de-yellowstone-e-parque-nacional-de-yosemite>. Acesso em 24 jan. 2012.

BRASIL. Lei no 9.985, de 18 de Julho de 2000. Regulamenta o artigo 225, $\S 1^{\circ}$, incisos I, II, III e VII da Constituição Federal, institui o Sistema Nacional de Unidades de Conservação da Natureza e dá outras providências. Ministério do Meio Ambiente, Brasília. Disponível em <www.mma.gov.br/port/sbf/dap/doc/snuc.pdf >. Acesso em 27 jan. 2012.

CONDE, C. A. R. Estrada-parque, uma estratégia sustentável. Revista Pós. São Paulo, v. 16, n. 25, 2009.

DOUROJEANNI, M. J. Estradas-parque, uma oportunidade pouco explorada para o turismo no Brasil. Revista Natureza e Conservação. v. 1, n. 1, 2003.

IBAMA. Instituto Brasileiro do Meio Ambiente e Recursos Naturais Renováveis. Marco Conceitual das Unidades de Conservação Federais do Brasil. Brasília: IBAMA, 1997.

ICMBio. Instituto Chico Mendes de Conservação da Biodiversidade. Relatório sobre Programa de Turismo nos Parques. Brasília: ICMBio, 2008.

ICMBio. Instituto Chico Mendes de Conservação da Biodiversidade. Projeto de Ampliação do Parque Nacional do Viruá. Brasília, 1010. Disponível em $<$ http://www.icmbio.gov.br/portal/images/stories/o-que-

fazemos/estudoampliacaoparnavirua.pdf >. Acesso em 11 de agosto de 2015.

ICMBio. Instituto Chico Mendes de Conservação da Biodiversidade. Biodiversidade. Disponível em $<$ www.icmbio.gov.br/portal/biodiversidade/unidades-de-conservacao/biomasbrasileiros.html>. Acesso em 11 de agosto de 2015.

ICMBio. Instituto Chico Mendes de Conservação da Biodiversidade. Relatório de Gestão 2013. $\quad$ Disponível em $<$ http://www.icmbio.gov.br/portal/images/stories/o-quesomos/relatoriogestaoicmbio2013 .pdf>. Acesso em 11 de agosto de 2015.

JORGE PÁDUA, M. T. Turismo nos parques. Publicado em 05 nov. 2010. Disponível em <www.oeco.com.br>. Acesso em 25 jan. 2012.

JORGE PÁDUA, M. T. Sistema Brasileiro de Unidades de Conservação: De onde viemos e para onde vamos? In: I Congresso Brasileiro de Unidades de Conservação, 1997, Curitiba - PR. Anais. Curitiba:IAP-UNILIVRE, 1997. 214236.

MALHOTRA, N. K. Pesquisa de marketing: uma orientação aplicada. Porto Alegre, Bookman, 2006. 
MILANO, M. S. Conceitos básicos e princípios gerais de planejamento, manejo e administração. In: Curso de Planejamento e Manejo de Áreas Naturais Protegidas. Guaraqueçaba, 2005.

MITTERMEIER, R. A. et al. Uma breve história da conservação da biodiversidade no Brasil. Revista Megadiversidade. v. 1, n. 1, 2005.

MMA. Ministério do Meio Ambiente. Projeto de Ampliação do Parque Nacional do Viruá. Brasília: MMA, 2010.

MMA. Ministério do Meio Ambiente. Programa de Turismo nos Parques. Brasília: MMA, 2008.

MMA. Ministério do Meio Ambiente. Cadastro Nacional de Unidades de Conservação. Disponível em http://www.mma.gov.br/areasprotegidas/cadastro-nacional-de-ucs/dados-consolidados. Acesso em 11 de agosto de 2015

SERRA, M.A.; GARCIA, E.M.; ORTIZ, R.A.; HASENCLEVER, L.; MORAES, G.I. $A$ valoração contingente como ferramenta de economia aplicada a valoração ambiental: o caso da Estrada Parque Pantanal. Planejamento e Políticas Públicas - PPP, ㄲo27. Jun./Dez. 2004.

TAKAHASHI, L.Y. Conceitos Gerais sobre Conservação da Natureza. Guaraqueçaba: Fundação O Boticário de Proteção à Natureza, 2006.

UICN. União Internacional para a Conservação da Natureza e dos Recursos Naturais. Estratégia Mundial para a Conservação. São Paulo, 1984.

Leila de Sena Cavalcante: Instituto Federal de Educação, Ciência e Tecnologia de Roraima, Boa Vista, RR, Brasil.

E-mail: leilasena@ifrr.edu.br.

Link para o currículo Lattes: http://lattes.cnpq.br/3367888642872826

Paulo dos Santos Pires: Universidade do Vale do Itajaí, Balneário Camboriú, $\mathrm{SC}$, Brasil.

E-mail: pires@univali.br.

Link para o currículo Lattes: http://lattes.cnpq.br/3480178807550158

Data de submissão: 29 de maio de 2012

Data de recebimento de correções: 17 de agosto de 2015

Data do aceite: 17 de agosto de 2015

Avaliado anonimamente 